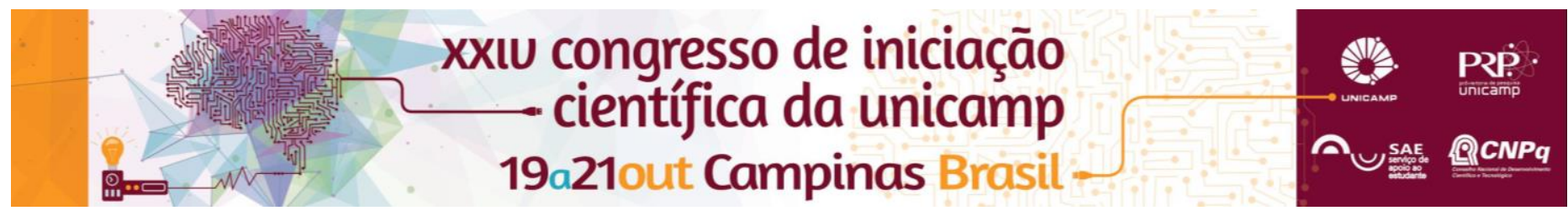

\title{
Proposta para estudo de um sistema híbrido de produção para estoque e para atendimento a pedidos em uma empresa de manufatura na região de Limeira
}

\section{Lailla Nunes de Oliveira Santos*}

\section{Resumo}

O objetivo primário desta pesquisa é realizar um estudo de caso único em uma empresa de manufatura na região de Limeira para avaliar os resultados da sua estratégia de produção sobre um sistema híbrido para estoque e atendimento de pedidos de cliente. O método proposto neste projeto de pesquisa foi o estudo de caso. A utilização de um sistema híbrido MTS/MTO permite a redução de até $65 \%$ dos custos dos sistemas que utilizam apenas um destes métodos de produção. Na maioria dos casos, a decisão sobre o sequenciamento depende da quantidade de pedidos MTS/MTO.

\section{Palavras-chave:}

Sistema Híbrido de Produção, Produção por Encomenda, Produção por Estoque.

\section{Introdução}

O setor industrial está cada vez mais competitivo. Flexibilidade, tempo de resposta, custo e qualidade são fatores decisivos para adquirir vantagem no mercado. As pesquisas de Kanda, Takahashi e Morikawa (2015) e Almehdawe e Jewkes (2013) apontam que as empresas buscam maior variedade de produtos e menores lead times, sem perder a qualidade e prejudicar os custos.

Os sistemas make-to-stock (MTS) e make-to-order (MTO) funcionam separadamente dentro das organizações, porém, na maioria dos casos não permitem que as mesmas atinjam todo seu potencial. O sistema híbrido MTS/MTO tem se destacado no setor industrial, pois pode proporcionar ampliação da eficiência em toda produção, consequentemente, em toda a organização.

O objetivo primário desta pesquisa é realizar um estudo de caso único em uma empresa de manufatura na região de Limeira para avaliar os resultados da sua estratégia de produção sobre um sistema híbrido para estoque e atendimento de pedidos de cliente.

\section{Resultados e Discussão}

O método proposto neste projeto de pesquisa foi o estudo de caso. Deste modo, houve o levantamento de informações, a partir de pesquisas bibliográficas, e o confronto das mesmas com conhecimento teórico acumulado anteriormente e no período da pesquisa, método sugerido por Ludke e André (1986). Entretanto, o projeto de pesquisa não foi concluído por desistência da aluna.

O resultado obtido foi a revisão bibliográfica de diversos autores sobre os temas gestão de operações, administração da produção, sistemas de produção híbrido, produção por encomenda e produção por estoques.

Para Kerkkänen (2007), a formulação de uma estratégia para solucionar problemas de produção e estoque no sistema híbrido envolve muitos elementos para e encontrar a alternativa mais adequada. Para demonstrar a necessidade de comunicação e entrosamento dentro do sistema, é preciso promover o entendimento do processo e dos efeitos das decisões tomadas.

A atual tendência, segundo Almehdawe e Jewkes (2013), é a montagem parcial do produto e estocá-lo para finalizá-los com a customização de acordo com as exigências dos clientes. Ou seja, as empresas estão utilizando um estoque intermediário para diminuir tempo de entrega dos produtos.
A utilização de um sistema híbrido MTS/MTO permite a redução de até $65 \%$ dos custos dos sistemas que utilizam apenas um destes métodos de produção. Na maioria dos casos, a decisão sobre o sequenciamento depende da quantidade de pedidos MTS/MTO. Quando não há pedidos da produção por encomenda, a capacidade produtiva deve se voltar para abastecer os estoques de produtos vendidos por estoque para suprir demandas futuras. Quando existirem pedidos MTO, produzir estes pedidos é mais indicado a recarregar os estoques. Este método permite que o lead time seja utilizado como tempo de cobertura para o processo produtivo. (BEEMSTERBOER ET AL, 2016)

\section{Conclusões}

O uso do sistema híbrido de produção por estoques e por encomendas proporciona a maximização da capacidade produtiva, permitindo uso inteligente de recursos, a partir do estabelecimento correto entre os produtos a serem produzidos, o momento da produção e o sistema utilizado.

Com o estudo dos sistemas em questão, podemos obter estratégias de produção bem definidas, as quais reduzem o valor a ser investido na produção, pois geram o aumento da capacidade das operações e reduzem custos através da inovação na utilização dos recursos da organização. As mesmas também podem amplificar as receitas ao atender as necessidades e expectativas dos clientes e aumentar seus níveis de satisfação.

\section{Agradecimentos}

Agradeço o apoio do CNPq, do PIBIC e da PRP Unicamp.

ALMEHDAWE, Eman; JEWKES, Elizabeth. Performance analysis and optimization of hybrid manufacturing systems under a batch ordering policy. International Journal of Production Economics, v. 144, n. 1, p. 200-208, 2013 BEEMSTERBOER, Bart; LAND, Martin; TEUNTER, Ruud. Hybrid MTOMTS production planning: An explorative study. European Journal of Operational Research, v. 248, n. 2, p. 453-461, 2016.

KANDA, Shohei; TAKAHASHI, Katsuhiko; MORIKAWA, Katsumi. A Flexible Service Rule for the Dynamic Make-to-Stock/Make-to-order Hybrid Production System. Procedia Manufacturing, v. 2, p. 46-50, 2015.

KERKKÄNEN, Annastiina. Determining semi-finished products to be stocked when changing the MTS-MTO policy: Case of a steel mill. International Journal of Production Economics, v. 108, n. 1, p. 111-118, 2007.

LÜDKE, Menga; ANDRÉ, Marli EDA. Pesquisa em educação: abordagens qualitativas. Editora Pedagógica e Universitária, 1986. 